\title{
Do metastatic colorectal cancer patients who present with late relapse after curative surgery have a better survival?
}

\author{
V T Broadbridge ${ }^{1}$, C S Karapetis ${ }^{2,3}$, C Beeke ${ }^{2}$, R J Woodman ${ }^{2,3}$, R Padbury ${ }^{2,3}$, G Maddern ${ }^{1,4}$, S W Kim ${ }^{2,3}$, \\ D Roder ${ }^{5}$, P Hakendorf ${ }^{2,3}$ and T J Price ${ }^{\star, 1,4}$ \\ ${ }^{1}$ Department of Medical Oncology, The Queen Elizabeth Hospital, Woodville, South Australia, Australia; ${ }^{2}$ Department of Medical \\ Oncology and Surgery, Flinders Medical Centre, Bedford Park, South Australia, Australia; ${ }^{3}$ Flinders University, Bedford Park, South \\ Australia, Australia; ${ }^{4}$ School of Medicine, University of Adelaide, Adelaide, South Australia, Australia and ${ }^{5}$ Division of Health \\ Sciences, University of South Australia, City East Campus, Adelaide, South Australia, Australia
}

Background: Patients who relapse after potentially curative surgery for colorectal cancer tend to relapse within 5 years. There is, however, a group of patients who relapse beyond 5 years after resection and this late relapsing group may have a different behaviour and prognosis.

Methods: We analysed data from a prospective population-based registry to compare the characteristics and survival of relapsed patients with metachronous $m C R C$. Patients were categorised into relapse at $<2,2-5$ and $>5$ years following their initial surgery. Univariate log-rank tests and multivariate Cox regression was performed to determine whether time to relapse (TTR) and other factors were associated with overall survival (OS).

Results: A total of 750 metachronous $m C R C$ patients were identified. In all, $56 \%$ relapsed $\leqslant 2$ years, $32.4 \%$ at $2-5$ years and $11.6 \%$ $>5$ years. Median survival time from the time of diagnosis of mCRC for the three groups was 17.6, 26.1 and 27.5 months, respectively. Short TTR ( $<2$ years) was significantly associated with survival $(H R=0.75,95 \%$ confidence interval $(C l)=0.60-0.93$ and $\mathrm{HR}=0.73,95 \% \mathrm{Cl}=0.53-1.01$, respectively, for $2-5$ and $>5$ years vs $<2$ years, $P<0.05)$. However, there was no significant difference in survival between patients who relapsed at 5 years or later compared with those who relapsed between 2 and 5 years $(\mathrm{HR}=0.98,95 \% \mathrm{Cl}=0.69-1.38, P=0.90)$.

Conclusion: TTR within 2 years is an independent predictor of shorter survival time for $\mathrm{mCRC}$ patients who experience a relapse. These data do not support the hypothesis that patients who have late relapse late ( $>5$ years) have a 'better' biology or survival compared with patients with a TTR of 2-5 years.

Colorectal cancer remains the one of the most common causes of cancer death worldwide (Globocan, 2008). Eighty percent of newly diagnosed colorectal cancers are diagnosed at an early stage and are primarily treated by surgical resection, which is associated with low recurrence rates and high survivals. However, despite surgery and adjuvant treatment with chemotherapy, the risk of recurrence for stages II or III disease is $40 \%$ (Kjeldsen et al, 1997). The risk of recurrence and prognosis of colon cancer is dependent on the pathologic stage, the 5-year survival for stage I colon cancer is approximately $93 \%$, but this figure ranges from $72 \%$ to $85 \%$ for stage II (O'Connell et al, 2004). Stage III patients are stratified into three subgroups with different 5-year overall survival (OS), which have been reported to range from: $83.4 \%$ for IIIa to $64.1 \%$ for IIIb, and $44.3 \%$ for IIIc (O’Connell et al, 2004).

Intensive surveillance programmes are recommended after surgical resection to detect early asymptomatic recurrences and 
increase the proportion of patients who may be eligible for further curative therapy (Bruinvels et al, 1994; Mulcahy and Benson 2002; Desch et al, 2005). Various meta-analyses have shown that this results in survival benefit (Jeffrey et al, 2002; Renehan et al, 2002; Figueredo et al, 2003). Patients with oligometastatic recurrence involving liver or lung can proceed with metastatectomy and achieve 35-40\% 5-year survival rates (McAfee et al, 1992; Goldberg et al, 1998; Ike et al, 2002; Rizk and Downey 2002).

Prognostic factors for risk of recurrence include presence of lymphovascular or perineural invasion, lymph nodes involvement and age. Over $90 \%$ of recurrences develop within 5 years, most within the first 2-3 years (Sargent et al, 2009). Multiple studies have found that shorter disease-free interval (DFI), which is defined as the duration between colon cancer and development of metastasis is associated with worse prognosis and shorter OS (Kaiser et al, 2006; Takahashi et al, 2006; Lin et al, 2009; Onaitis et al, 2009). There is, however, a group of patients who relapse beyond 5 years after resection for whom there is little information about their prognosis or OS. This late relapsing group may have a different behaviour and late recurrence may be associated with a better prognosis. We have explored outcomes for these late relapsing patients, in a larger population from our metastatic colorectal cancer database in South Australia.

\section{MATERIALS AND METHODS}

A retrospective cohort study from the prospective populationbased $\mathrm{mCRC}$ registry was conducted comparing the characteristics and survival of patients with metachronous (m) mCRC who present with recurrent disease. Data concerning patient demographics, surgical and oncological management, and relapse rate were obtained from the South Australian Cancer Registry. The defined period of follow-up was between 01 February 2006 and 31 August 2011.

Patients were categorised into three cohorts reflecting their time to first recurrence following initial surgery for primary colorectal cancer: < 2 years (cohort A), 2-5 years (cohort B) and $>5$ years (cohort C). Follow-up time for survival was defined as being from the date of colorectal cancer recurrence until the date of death. Patients who were still alive at the end of the defined period of follow-up were censored. Patient characteristics at the time of diagnosis were compared using ANOVA for continuous variables and $\chi^{2}$ test of independence for categorical variables.

A multivariate binary logistic regression model was also used to determine the independent associations between the patient characteristics and whether or not they were in cohort C.

Univariate log-rank tests and multivariate Cox regression were performed to determine whether time to relapse (TTR) and other factors (age, left-sided primary, prior adjuvant chemotherapy, chemotherapy for metastatic disease, liver resection, liver metastasis, lung metastasis, stage at diagnosis and histopathological grade) were associated with OS. Age was used as a continuous variable. Age was included in the multivariate model $a$ priori. A global test of the proportional hazards assumption and a test for each individual covariate were used to ensure model fit of the final model. The alpha level for statistical significance was chosen as 0.05 . Hazard ratios are provided with $95 \%$ confidence intervals (CIs). A sensitivity analysis of survival by cohorts $<1,1-2,2-3$, 3-5 and $>5$ years since diagnosis was also undertaken.

\section{RESULTS}

A total of 750 (34\%) patients out of the total 2084 in the database with colorectal cancer had metachronous disease with recurrence after initial curative intent treatment. Patient characteristics are summarised in Table 1. The proportion of patients in each cohort was as follows: cohort A 55.6\%, cohort B 32.5\% and cohort C $11.6 \%$. Median ages were 73 for cohorts A and B and 79 years for cohort C. Overall, a majority of (54-65\%) patients in each cohort had left-sided primary. Age (years) at diagnosis $(\mathrm{OR}=0.39,95 \%$ $\mathrm{CI}=1.11,1.05 ; \quad P=0.002)$ and stage at diagnosis $(\mathrm{OR}=4.1$ (1.6, 10.5); $P=0.004$ for stage A vs stage $\mathrm{C}$ and $\mathrm{OR}=1.6$ (1.00-2.58); $P=0.05$ for stage $B$ vs stage C) were the only independent predictors of late stage progression (cohort $\mathrm{C}$ ).

Cohort A had the highest proportion of Duke's C (65\%, $P<0.001)$ cancer, poorly differentiated pathology $(26 \%, P=0.002)$ and liver metastasis $(32.7 \%, P=0.006)$ when compared with cohorts $\mathrm{B}$ and $\mathrm{C}$ (Table 1). This also correlated with a higher proportion of patients in cohort A receiving prior adjuvant therapy $(45 \%, P=0.009)$. The rate of chemotherapy given for metastatic disease was $54 \%(P=0.03)$ and $18 \%$ of cohort A underwent a hepatic resection for liver metastasis $(P<0.05)$.

Cohort B had $63.5 \%$ with a left-sided cancer, $49 \%$ were Duke's C and $17 \%$ had poorly differentiated adenocarcinoma (Table 1 ). In all, $21.3 \%$ had liver only recurrence and $39 \%$ had adjuvant therapy after diagnosis of initial CRC with 54\% receiving chemotherapy for metastatic disease and $12 \%$ having liver surgery.

Cohort $\mathrm{C}$ had highest proportion of primary tumours arising from left side of the colon $(65 \%, P=0.02)$ with the lowest proportion of a poorly differentiated tumour (12.5\%), metastases to liver $(25.3 \%)$ or lung only $(9.2 \%)$, prior adjuvant therapy $(28 \%$, $P=0.009)$, systemic chemotherapy for metastatic disease $(40 \%)$ or had hepatic surgery $(10 \%)$, in comparison with cohorts A and B (Table 1). There was also a trend to a higher rate of disease beyond single site lung or liver recurrence ( $64 \%$ vs $40 \%$ cohort B and $44 \%$ cohort A). The percentage of patients with $>2$ sights of metastasis were low and were similar in all cohorts $(6 \%$ vs $10 \%$ vs $8 \%$, respectively). Median OS, from the time of diagnosis of the recurrence, was 17, 24.8 and 26.5 months for cohorts A, B and C, respectively. There was, however, no significant difference in survival between cohorts $\mathrm{B}$ and $\mathrm{C}$ patients $(\mathrm{HR}=0.9, P=0.90)$. Patients with prior Duke's A disease who relapsed had a better outlook with higher proportion of survival compare with Dukes $\mathrm{B}$ and $\mathrm{C}$.

Table 2 displays the results of the univariate and multivariate Cox regression analysis. In univariate analysis, age in years $(\mathrm{HR}=1.02, P<0.001)$, TTR category $(\mathrm{HR}=0.77$, and $\mathrm{HR}=0.81$, respectively, for cohorts $\mathrm{B}$ and $\mathrm{C} v s$ cohort $\mathrm{A}, P=0.04$ overall), liver resection $(\mathrm{HR}=0.21, P<0.001)$, liver only metastasis $(\mathrm{HR}=0.69, P=0.001)$, chemotherapy for metastatic disease (HR $=0.80, P=0.016)$, histology grade $(P<0.001)$ and left-sided malignancy $(\mathrm{HR}=0.73, P=0.001)$ were significant independent predictors of OS. Prior adjuvant chemotherapy $(\mathrm{HR}=0.84$, $P=0.078$ ) and stage at diagnosis (Duke's $\mathrm{A}=0.37$, Duke's $\mathrm{B}=0.93$ and Duke's $\mathrm{D}=1.19$ vs Duke's $\mathrm{C}, P=0.054$ ) were also significant borderline predictors of survival at the $10 \%$ alpha level.

In the multivariate analysis, age $(\mathrm{HR}=1.01, P=0.001)$, liver resection $(\mathrm{HR}=0.22, P<0.001)$, lung metastasis $(\mathrm{HR}=0.69$, $P=0.026)$, histology grade $(P=0.02$ overall $)$ and TTR $(\mathrm{HR}=0.74,95 \% \mathrm{CI}=0.60-0.91$ for $2-5$ years $v s<2$ years and $\mathrm{HR}=0.72,95 \% \mathrm{CI}=0.53-0.99$ for $>5$ years $v s \leqslant 2$ years, $P=0.04$ overall; Figure 1) were significantly associated with OS. There was, however, no significant difference in survival between patients who relapsed at 5 years or later compared with those who relapsed between 2 and 5 years $(\mathrm{HR}=0.98,95 \% \mathrm{CI}=0.70-1.38, P=0.91)$.

In sensitivity analysis using categories of $<1,1-2,2-3,3-5$ and $>5$ years for the TTR, there was a significant difference overall in survival $(P=0.03)$. Patients who relapsed between 2 and 3 years had significantly better survival than those who relapsed within 1 year from diagnosis $(\mathrm{HR}=0.69,95 \% \mathrm{CI}=0.51,0.93 ; P=0.01$; Figure 2). 


\begin{tabular}{|c|c|c|c|c|}
\hline & $\begin{array}{c}\text { Group A } \\
\text { (TTR }<2 \text { years) } \\
\mathbf{N}=\mathbf{4 1 9}\end{array}$ & $\begin{array}{c}\text { Group B } \\
\text { (TTR 2-5 years) } \\
\mathbf{N}=\mathbf{2 4 4}\end{array}$ & $\begin{array}{c}\text { Group C } \\
\text { (TTR }>5 \text { years) } \\
\mathbf{N}=87\end{array}$ & $\boldsymbol{P}$-value \\
\hline $\begin{array}{l}\text { Median age (range), years } \\
\text { Left-sided primary, } n(\%)\end{array}$ & $\begin{array}{l}72.9(22-99) \\
227(54.2)\end{array}$ & $\begin{array}{l}73.4(37-103) \\
155(63.5)\end{array}$ & $\begin{array}{l}78.5(47-96) \\
57(65.5)\end{array}$ & $\begin{array}{l}0.003 \\
0.02\end{array}$ \\
\hline \multicolumn{5}{|l|}{ Stage at diagnosis, $\boldsymbol{n}(\%)$} \\
\hline $\begin{array}{l}\text { A } \\
\text { B } \\
\text { C } \\
\text { Unknown } \\
\text { Poorly differentiated, } n(\%)\end{array}$ & $\begin{array}{c}4(1.0) \\
135(32.2) \\
272(64.9) \\
8(1.9) \\
111(26.5)\end{array}$ & $\begin{array}{c}14(5.7) \\
105(43.0) \\
120(49.2) \\
5(2.0) \\
42(17.2)\end{array}$ & $\begin{aligned} 7 & (8.1) \\
42 & (48.3) \\
38 & (43.7) \\
0 & (0.0) \\
11 & (12.6)\end{aligned}$ & $<0.001$ \\
\hline \multicolumn{5}{|l|}{ Primary site, $n(\%)$} \\
\hline $\begin{array}{l}\text { Colon } \\
\text { Rectal } \\
\text { Lung metastasis only, n (\%) } \\
\text { Liver metastasis only, n (\%) }\end{array}$ & $\begin{array}{r}154(36.8) \\
265(63.3) \\
42(10.0) \\
137(32.7)\end{array}$ & $\begin{array}{r}93(38.1) \\
151(61.9) \\
48(19.7) \\
52(21.3)\end{array}$ & $\begin{array}{c}38(43.7) \\
49(56.3) \\
8(9.2) \\
22(25.3)\end{array}$ & $\begin{array}{l}0.48 \\
0.001 \\
0.006\end{array}$ \\
\hline \multicolumn{5}{|l|}{ Prior adjuvant therapy, $n /$ total (\%) } \\
\hline $\begin{array}{l}\text { Stage A } \\
\text { Stage B } \\
\text { Stage C } \\
\text { Stage D } \\
\text { Total }\end{array}$ & $\begin{array}{r}1 / 4(25.0) \\
26 / 135(19.3) \\
159 / 272(58.5) \\
2 / 8(25.0) \\
188 / 419(44.9)\end{array}$ & $\begin{array}{c}0 / 14(0.0) \\
11 / 105(10.5) \\
85 / 120(70.8) \\
0 / 0(0.0) \\
96 / 244(39.3)\end{array}$ & $\begin{array}{c}0 / 7(0.0) \\
5 / 42(11.9) \\
19 / 38(50.0) \\
0 / 0(0.0) \\
24 / 87(27.6)\end{array}$ & 0.009 \\
\hline $\begin{array}{l}\text { Palliative chemotherapy, } n(\%) \\
\text { Hepatic surgery for metastasis, } n(\%)\end{array}$ & $\begin{array}{r}229(54.7) \\
77(18.4)\end{array}$ & $\begin{array}{r}131(53.7) \\
33(13.5)\end{array}$ & $\begin{array}{l}34(39.1) \\
10(11.5)\end{array}$ & $\begin{array}{r}0.03 \\
<0.05\end{array}$ \\
\hline
\end{tabular}

\section{DISCUSSION}

We have shown that a significant number of patients (11.6\%) relapse after potentially curative surgery beyond 5 years (i.e., after the standard recommended surveillance period). Despite perhaps a presumption that patients relapsing late may have a better outcome, our results suggest that their prognosis is similar to that for those who relapse between 2 and 5 years after surgery. These results have potential implications for surveillance programmes and for therapeutic interventions. It questions whether surveillance schedules should continue beyond 5 years to improve survival outcome by detecting recurrences early and metastatic disease that may be suitable for curative surgery.

The highest risk of recurrence is thought to occur within the first 3 years after initial surgery for resection of colonic cancer and is highest in Dukes B and C diseases (Bruinvels et al, 1994, Kjeldsen et al, 1997; Desch et al, 2005; Sargent et al, 2009). Tumour stage at diagnosis is a major prognostic factor and 5-year survival rates ranges from $93 \%$ for AJCC stage 1 and decreases to $43 \%$ for stage 3C disease (O'Connell et al, 2004). Intensive surveillance is recommended by ASCO and NCCN guidelines with regular review, CEA monitoring and CT especially in the first 3 years for early detection of metastatic disease or local recurrence so that surgical resection is more likely to be an option for cure and improve survival (Desch et al, 2005). In all, 56\% of patients with metachronous mCRC from our registry relapsed within 2 years of the initial resection of colon cancer. These patients had the following features: higher proportion of right-sided primary, stage III (and thus more likely to have received prior adjuvant chemotherapy), poorly differentiated carcinoma and liver only metastasis.
Stage remains one of the most important prognostic factors for survival. The result from our study is consistent with other studies with Duke's A patients having the best survival following relapse. Cohort A had the highest proportion of Duke's C disease of $65 \%$ and other adverse prognostic factors including poorly differentiated adenocarcinoma, highest proportion of liver and lung metastases and with this, the worst survival outcome of all three cohorts (Figure 3). As expected given the adverse features, cohort A also had the highest proportion of patients (45\%) who had received prior adjuvant chemotherapy and $54 \%$ ultimately received palliative chemotherapy. Survival remained poor, however, for this cohort, which is consistent with other studies showing patients with early relapse have worse outcome (Kaiser et al, 2006). The observation of a higher proportion of right-sided primary is interesting given recent evidence that side of primary may be prognostic although the data do vary (Brule et al, 2013; Missiaglia et al, 2013).

Retrospective observational studies have shown that patients who had shorter DFI ( $<12$ months) from the primary colon cancer to appearance of first metastasis has poorer outcome (Fong et al, 1997; Kaiser et al, 2006; Lin et al, 2009; Gonzalez et al, 2012). One study found that the recurrence interval was inversely correlated with the initial tumour stage and that the use of adjuvant treatment did not prolong the interval, that is, delay the onset of recurrent cancer (Kaiser et al, 2006). For patients who were able to undergo metastatectomy (liver or lung), shorter DFI from the time of metastatectomy to recurrence ( $<6$ or 12 months) are also associated with poorer survival (Takahashi et al, 2006; Onaitis et al, 2009; Takakura et al, 2010; Gonzalez et al, 2012). Our exploratory sensitivity analysis assessing outcomes by 12 -month periods further supports the evidence for poor outlook for patients 
Table 2. Hazard ratios for survival according to patient characteristics using univariate and multivariate Cox regression

\begin{tabular}{|c|c|c|c|c|}
\hline & \multicolumn{2}{|c|}{ Univariate analysis } & \multicolumn{2}{|c|}{ Multivariate analysis } \\
\hline & $\mathrm{HR}(95 \% \mathrm{Cl})$ & $P$-value & HR $(95 \% \mathrm{Cl})$ & $\boldsymbol{P}$-value \\
\hline \multicolumn{5}{|l|}{ Time to progression } \\
\hline $\begin{array}{l}\text { Cohort A ( }<2 \text { years) } \\
\text { Cohort B ( } 2-5 \text { years) } \\
\text { Cohort C ( }>5 \text { years) }\end{array}$ & $\begin{array}{c}1.00 \\
0.77(0.63,0.95) \\
0.81(0.59,1.11)\end{array}$ & $\begin{array}{l}- \\
0.02 \\
0.19\end{array}$ & $\begin{array}{c}1.00 \\
0.74(0.60,0.91) \\
0.72(0.53,0.99)\end{array}$ & $\begin{array}{c}- \\
0.005 \\
0.042\end{array}$ \\
\hline $\begin{array}{l}\text { Age (years) } \\
\text { Left-sided tumour (yes vs no) }\end{array}$ & $\begin{array}{l}1.02(1.01,1.03) \\
0.73(0.61,0.88)\end{array}$ & $\begin{array}{l}<0.001 \\
0.001\end{array}$ & $1.01(1.006,1.022)$ & 0.001 \\
\hline \multicolumn{5}{|l|}{ Stage at diagnosis } \\
\hline $\begin{array}{l}\text { A } \\
\text { B } \\
\text { C } \\
\text { Unknown }\end{array}$ & $\begin{array}{c}0.37(0.17,0.77) \\
0.93(0.76,1.12) \\
1.00 \\
1.19(0.63,2.23)\end{array}$ & $\begin{array}{c}0.009 \\
0.43 \\
- \\
0.59\end{array}$ & & \\
\hline \multicolumn{5}{|l|}{ Histological grade } \\
\hline $\begin{array}{l}\text { Well defined } \\
\text { Moderate } \\
\text { Poorly differentiated } \\
\text { Not stated }\end{array}$ & $\begin{array}{c}0.92(0.34,2.51) \\
0.67(0.54,2.51) \\
1.00 \\
1.04(0.65,1.67)\end{array}$ & $\begin{array}{c}0.88 \\
<0.001 \\
- \\
0.88\end{array}$ & $\begin{array}{c}1.45(0.53,3.98) \\
0.74(0.60,0.91) \\
1.00 \\
0.99(0.61,1.61)\end{array}$ & $\begin{array}{c}0.47 \\
0.005 \\
- \\
0.98\end{array}$ \\
\hline \multicolumn{5}{|l|}{ Primary site } \\
\hline $\begin{array}{l}\text { Colon } \\
\text { Rectal }\end{array}$ & $\begin{array}{c}1.18(0.97,1.43) \\
1.00\end{array}$ & 0.10 & & \\
\hline $\begin{array}{l}\text { Lung metastasis only } \\
\text { Liver metastasis only } \\
\text { Prior adjuvant therapy } \\
\text { Palliative chemotherapy } \\
\text { Hepatic surgery for metastasis }\end{array}$ & $\begin{array}{l}0.79(0.57,1.08) \\
0.69(0.56,0.86) \\
0.84(0.70,1.02) \\
0.80(0.66,0.96) \\
0.21(0.14,0.32)\end{array}$ & $\begin{array}{c}0.15 \\
0.001 \\
0.08 \\
0.02 \\
<0.001\end{array}$ & $0.69(0.50,0.96)$ & $<0.001$ \\
\hline
\end{tabular}

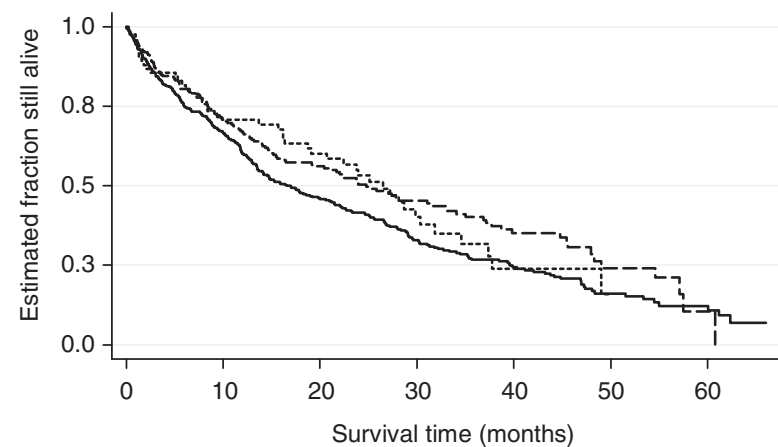

Number at risk

$\begin{array}{cccccccc}<2 \text { years } & 418 & 243 & 138 & 84 & 52 & 21 & 9 \\ 2-5 \text { years } & 242 & 143 & 92 & 57 & 31 & 10 & 2 \\ >5 \text { years } & 86 & 50 & 37 & 17 & 5 & 0 & 0\end{array}$

- Time to relapse $<2$ years ----- Time to relapse $2-5$ years
-.........- Time to relapse $>5$ years

Figure 1. Cox regression adjusted survivor function according to time between initial diagnosis and relapse $(<2,2-5$ and $>5$ years).

who relapse within 12 months of resection (Figure 2), although statistically this only reached significance at 3 years and beyond. Patients whose cancer recurs within first 12 months are likely to

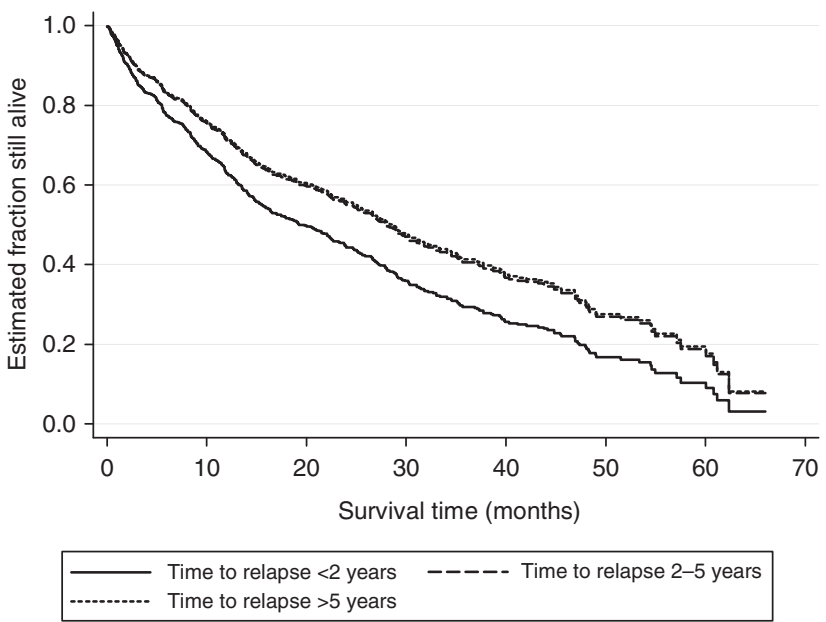

Figure 2. Sensitivity TTR analysis.

have a different biology to those who recur after 12 months. The nature of the cancer is likely to be more aggressive and less likely to be impacted on by chemotherapy. The other explanation as to why this patient group have worse survival may be that they have a higher volume of occult metastatic disease, which therefore manifests sooner. Although we defined early relapse for our 


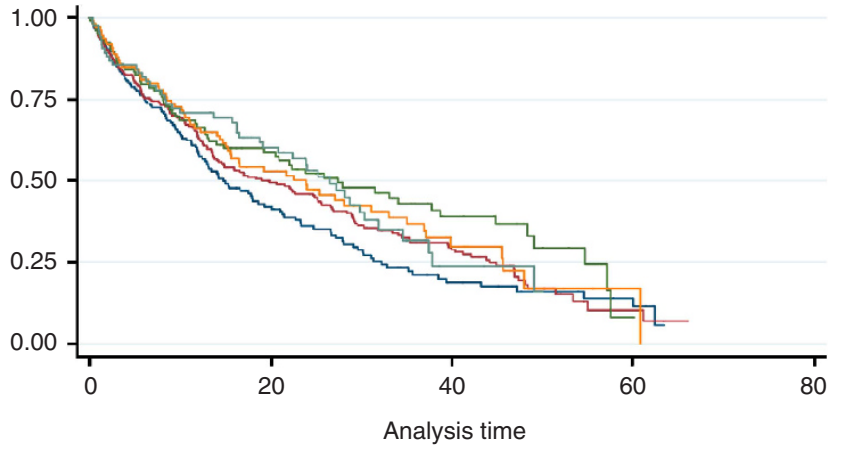

$\begin{aligned} \longrightarrow \operatorname{ttp} \_c a t 5 & =0-1 \text { year } \longrightarrow \operatorname{ttp} \_ \text {cat } 5=1-2 \text { years } \\ \operatorname{ttp} \_c a t 5 & =2-3 \text { year } \longrightarrow \operatorname{ttp} \text { _cat } 5=3-5 \text { years } \\ \operatorname{ttp} \text { ccat5 } 5 & =5+\text { years }\end{aligned}$

Figure 3. Kaplan-Meier survival estimates for cohorts A, B and C.

primary analysis as TTR $<2$ years, our data do support these reports given the greater proportion of patients having higher stage pathology in this group. Patients who relapse early have been reported as more likely to have higher tumour volume and involvement of more organs, making it less likely they can undergo further curative resection (Takahashi et al, 2006). However, this was not reflected in the results of our study with cohort A having a higher rate of liver resection, $18 \%$ compared with $10 \%$ for cohort C who relapsed late. This may reflect a different surgical practice in our state, but ultimately it does not seem to have impacted on outcome. Future biomarker studies from tissue banks will be important to differentiate patients who have aggressive biology and are thus destined to relapse early to avoid metastatectomy and potentially allow earlier use of palliative chemotherapy instead.

When comparing between cohorts B and C, there is no evidence that metachronous mCRC patients with later relapse have a better prognosis as there was no survival difference between these two cohorts. This is perhaps surprising as it is hypothesised that metastatic CRC that recurs after 5 years may have more indolent biology and thus may have a better prognosis and survival. The potential reasons why this has not been shown here include: patients in cohort $\mathrm{C}$ are older at diagnosis of recurrence and therefore have poorer survival or that surveillance is less intensive and early detection is not achieved so metastatectomy is not an option for this group. Cohort $\mathrm{C}$ had the lowest proportion of patient who received hepatic surgery or palliative chemotherapy in comparison with the other two cohorts, which may reflect that this patient group, when they do recur, do worse as they are likely to be less suitable to have curative surgery or to receive chemotherapy. Ideally, a profile of patients at risk of late recurrence would assist the clinician decide on who may benefit from longer surveillance. Although there are differences in age (cohort $\mathrm{C}$ older), primary site (more left-sided primary cohort C) and initial stage (greater Duke's $\mathrm{B}$ in cohort $\mathrm{C}$ ), these clinicopathological factors would generally argue against longer intense follow-up and ultimately biological factors are likely to be more important. These results will hopefully come from large randomised adjuvant studies and form the basis of models to predict patterns of relapse.

There are some limitations with this study, one that it is an observational study, albeit from a prospectively collected database. We also have not assessed disease-specific mortality in this analysis, instead using all-cause mortality, which would not be uncommon in studies of advanced disease. There is a need to potentially consider the impact of age-related mortality, although in the setting of metastatic colorectal cancer it is likely to have only a small influence on all-cause mortality. This may be more of an issue in, for example, adjuvant registries where the follow-up and survival times are longer. Finally, because of the restricted access in Australia at the time of this analysis to biological agents, most of the patients in the registry would have not received targeted therapies (bevacizumab and cetuximab) with their initial chemotherapy. This may have an impact on altering the behaviour of the mCRC and affect survival.

In conclusion, in this analysis we have confirmed that liver resection for hepatic metastatic disease and the presence of lung only metastatic disease are both positive predictors of OS. Patients who relapse within 2 years of a potentially curative primary resection have an inferior outcome. Importantly despite what may seem intuitive, we have demonstrated that patients who relapsed late ( $>5$ years) compared with those who relapse between 2 and 5 years beyond initial curative intent surgery have equivalent after relapse survival. Further analysis of this data with time may reveal whether the use of targeted therapies has an impact on OS by altering the behaviour of colon cancer.

\section{CONFLICT OF INTEREST}

The authors declare no conflict of interest.

\section{REFERENCES}

Bruinvels DJ, Stiggelbout AM, Kievit J, Van Houwelingen HC, Habbema JDF, Van de Velde CJH (1994) Follow-up of patients with colorectal cancer. Ann Surg 219: 174-182.

Brule SY, Jonker DJ, Karapetis CS, O'Callaghan CJ, Moore MJ, Wong R, Tebbutt NC, Underhill C, Yip D, Zalcberg JR, Tu T, Goodwin RA (2013) Location of colon cancer (right-sided [RC] versus left-sided [LC]) as a predictor of benefit from cetuximab (CET): NCIC CTG CO.17. J Clin Oncol 31(suppl): abstr 35280.

Desch CE, Benson AB, Somersfield MR, Flynn PJ, Krause C, Loprinzi CL, Minsky BD, Pfister DG, Virgo KS, Petrelli NJ (2005) Colorectal cancer surveillance: 2005 update of an American Society of Clinical Oncology practice guideline. J Clin Oncol 23: 8512-8519.

Figueredo A, Rumble RB, Maroun J, Earle CC, Cummings B, Mcleod R, Zuraw L, Zwall C. and the members of the Gastrointestinal Cancer Disease Site Group of Cancer Care Ontario's Program in Evidence-based Care (2003) Follow-up of patients with curatively resected colorectal cancer: a practice guideline. BMC Cancer 3: 26.

Fong BY, Cohen AM, Fortner JG, Enker WE, Turnbull AD, Colt DG, Marrero AM, Prasad M, Blumgart LH, Brennan MF (1997) Liver resection for colorectal metastases. J Clin Oncol 15: 938-946.

Globocan (2008) http://globocan.iarc.fr/accessed 19th June 2012.

Goldberg RM, Fleming TR, Tangen CM, Moertel CG, Macdonald JS, Haller DG, Laurie JA (1998) Surgery for recurrent colon cancer: strategies for identifying resectable recurrence and success rates after resection. Eastern Cooperative Oncology Group, The North Central Cancer Treatment Group and the Southwest Oncology Group. Ann Intern Med 129: 27-35.

Gonzalez M, Robert JH, Halkic N, Mentha G, Roth A, Perneger T, Ris HB, Gervaz P (2012) Survival after lung metastasectomy in colorectal cancer patients with previously resected liver metastases. World J Surg 36: 386-391.

Ike H, Shimada H, Ohki S, Togo S, Yamaguchi S, Ichikawa Y (2002) Results of aggressive resection of lung metastases from colorectal carcinoma detected by intensive follow-up. Dis Colon Rectum 45: 468-473.

Kaiser AM, Kang JC, Chan LS, Beart RW (2006) The prognostic impact of the time interval to recurrence for the mortality in recurrent colorectal cancer. Colorectal Dis 8: 696-703.

Kjeldsen BJ, Kronborg O, Fenger C, Jorgensen OD (1997) The pattern of recurrent colorectal cancer in a prospective randomised study and the characteristics of diagnostic tests. Int J Colorectal Dis 12: 329-334.

Lin BR, Chang TC, Lee YC, Lee PH, Chang KJ, Liang JT (2009) Pulmonary resection for colorectal cancer metastases: duration between cancer onset and lung metastasis as an important prognostic factor. Ann Surg Oncol 16: $1026-1032$. 
McAfee MK, Allen MS, Trastek VF, Ilstrup DM, Deschamps C, Pairolero PC (1992) Colorectal lung metastases: results of surgical excision. Ann Thorac Surg 53: 780-786.

Missiaglia E, Jacobs B, Di Narzo AF, Soneson C, Roth A, Bosman F, d'Ario G, Klingbiel D, Yan P, Delorenzi M, Tejpar S (2013) Proximal and distal colon tumors as distinct biologic entities with different prognoses. J Clin Oncol 31(suppl): abstr 3526.

Mulcahy MF, Benson III AB (2002) Post treatment surveillance of colon and rectal cancers. J Clin Oncol 646-651.

O'Connell JB, Maggard MA, Ko CY (2004) Colon cancer survival rates with the new American Joint Committee on Cancer sixth edition staging. J Natl Cancer Inst 96: 1420-1425.

Onaitis MW, Petersen RP, Haney JC, Saltz L, Park B, Flores R, Rizk N, Bains MS, Dycoco J, D’Amico TA, Harpole DH, Kemeny N, Rusch VW, Downey R (2009) Prognostic factors for recurrence after pulmonary resection of colorectal cancer metastases. Ann Thorac Surg 87: 1684-1688.

Renehan AG, Egger M, Saunders MP, O’Dwyer ST (2002) Impact on survival of intensive follow up after curative resection for colorectal cancer: systematic review and meta-analysis of randomised trials. BMJ 324: 1-8.
Rizk NP, Downey RJ (2002) Resection of pulmonary metastases from colorectal cancer. Semin Thorac Cardiovas Surg 14: 29-34.

Sargent D, Sobrero A, Grothey A, O'Connell MJ, Buyse M, Andre T, Zheng Y, Green E, Labianca R, O'Callaghan C, Seitz JF, Francini G, Haller D, Yothers G, Goldberg R, De Gramont A (2009) Evidence for cure by adjuvant therapy in colon cancer: observations based on individual patient data from 20,898 patients on 18 randomized trials. J Clin Oncol 27: 872-877.

Takahashi S, Konishi M, Nakagohri T, Gotohda N, Saito N, Kinoshita T (2006) Short time to recurrence after hepatic resection correlates with poor prognosis in colorectal hepatic metastasis. Jpn J Clin Oncol 36: 368-375.

Takakura Y, Miyata Y, Okajima M, Okada M, Ohdan H (2010) Short diseasefree interval is a significant risk factor for intrapulmonary recurrence after resection of pulmonary metastases in colorectal cancer. Colorectal Disease 12: e68-e75.

This work is published under the standard license to publish agreement. After 12 months the work will become freely available and the license terms will switch to a Creative Commons AttributionNonCommercial-Share Alike 3.0 Unported License. 